\title{
Expression and significance of Wnt signaling components and their target genes in breast carcinoma
}

\author{
YANJIAO HE, ZHAOXIA LIU, CHAO QIAO, MIAOSHENG XU, JIN YU and GUANG LI \\ Department of Pathology, Beijing Tiantan Hospital, Capital Medical University, Beijing 100050, P.R. China
}

Received April 2, 2013; Accepted October 8, 2013

DOI: $10.3892 / \mathrm{mmr} .2013 .1774$

\begin{abstract}
The aim of this study was to investigate the expression of $\beta$-catenin, axin, cyclin D1 and c-myc, and their correlation with various clinicopathological factors of breast carcinoma. Using immunohistochemistry, the expression of axin, $\beta$-catenin, cyclin D1 and c-myc proteins was detected in 168 breast carcinomas and 40 normal breast tissue samples, as well as in 72 breast intraductal proliferative lesions. Correlations among the expression of these proteins with the clinicopathological factors of breast carcinomas were subsequently analyzed. Gene mutations of $\beta$-catenin (exon 3 ) in 44 cases of breast carcinoma were analyzed using polymerase chain reaction (PCR) followed by direct sequencing. In normal tissue, the epithelial cells demonstrated a marked membranous expression of $\beta$-catenin protein at cell-cell boundaries and positive axin expression; cyclin D1 and c-myc expression, however, were negative. The abnormal rate of $\beta$-catenin expression and the overexpression of cyclin D1 and c-myc were higher in breast carcinomas compared with breast cystic hyperplasia tissues. Positive axin expression levels were lower in breast carcinomas compared with breast intraductal proliferative lesions and normal breast tissues. Axin expression correlated inversely with tumor size, histological grade, clinical tumor, node, metastasis (TNM) stage and lymph node metastasis. The abnormal expression of $\beta$-catenin and the overexpression of cyclin D1 were correlated, and the overexpression of c-myc was correlated with tumor size, histological grade, clinical TNM stage and lymph node metastasis. The abnormal expression of $\beta$-catenin was correlated with the overexpression of cyclin D1, but not with the overexpression of c-myc. Lower levels of axin expression were correlated with higher levels of nuclear $\beta$-catenin expression. Mutations in the $\beta$-catenin gene were not detected in 44 cases of breast carcinoma. The abnormal expression of
\end{abstract}

Correspondence to: Dr Yanjiao He, Department of Pathology, Beijing Tiantan Hospital, Capital Medical University, 6 Tiantan Xili, Beijing 100050, P.R. China

E-mail: heyanjiao23@163.com

Key words: breast neoplasmas, Wnt signaling, axin, $\beta$-catenin, cyclin D1, c-myc $\beta$-catenin may be key in the carcinogenesis and progression of human breast carcinoma by upregulating the expression of cyclin D1. The abnormal expression of $\beta$-catenin, the reduced expression of axin, and the overexpression of cyclin D1 and c-myc may be useful markers for determining metastasis, providing a prognosis for human breast carcinoma and for guiding treatment.

\section{Introduction}

Breast cancer is one of the most common malignant diseases among females. In China, its morbidity rate increases annually while affecting patients at younger ages, making breast cancer an important current health issue. However, with recent advances in molecular oncology, cancer treatments are capable of targeting the signaling pathways of tumors. Recently, oncologists have been targeting the Wnt/ $\beta$-catenin signaling pathway as a method of treatment $(1,2)$.

The Wnt signaling pathway regulates cell fate, survival, proliferation and differentiation at various stages of mammalian development and pathology. Activation of the canonical Wnt signaling pathway results in the stabilization and nuclear accumulation of $\beta$-catenin and subsequent gene transcription. $\beta$-catenin, a multifunctional cytoplasmic protein, forms a dynamic complex with E-cadherin and acts as a key regulator in the Wnt signaling pathway (3-6) Several studies have demonstrated that the abnormal expression and mutations of $\beta$-catenin are observed in a wide range of human cancers, and are associated with tumorigenesis (3-5). Axin is an important negative regulator of the Wnt signaling pathway, which coordinates $\beta$-catenin phosphorylation and degradation (7). Certain studies have demonstrated that c-myc and cyclin D1 are important target genes for the Wnt signaling pathway and their overexpression is associated with the accumulation of $\beta$-catenin in numerous tumor types (3-5).

The mode of regulation of these molecules, with regard to breast cancer, remains unclear. It is important to determine their expression and investigate their regulation mechanisms for the prevention, treatment, and evaluation of human breast cancer. In the present study, the expression of axin, $\beta$-catenin, c-myc and cyclin D1, and the mutation of the $\beta$-catenin gene were detected. This study also examined the association between the expression levels and the clinicopathological factors for axin, $\beta$-catenin, c-myc and cyclin D1; axin mechanisms that regulate $\beta$-catenin and the downstream target gene were also analyzed. 


\section{Materials and methods}

Patients and specimens. In total, 168 breast cancer tissue specimens were collected for this study from 2005 to 2010 from the Department of Pathology, Beijing Tiantan Hospital Affiliated Capital Medical University (Beijing, China). Of these specimens, 82 were obtained from the left breast and 86 from the right. The mean age of the participants was 54.5 years (range, 27-82 years). Tumors were divided into three groups according to size: 56 patients had a tumor $<2 \mathrm{~cm}$ in diameter, 91 patients had tumors $2-5 \mathrm{~cm}$ in diameter and 21 patients had tumors $>5 \mathrm{~cm}$ in diameter. Histologically, 126 cases involved invasive ductal carcinoma, not otherwise specified (IDC, NOS), whereas 42 cases were classified according to other categories: 15 cases of invasive lobular carcinomas (ILC), six tubular carcinomas, three medullary carcinomas, eight mucinous carcinomas, three invasive papillary carcinomas, one apocrine carcinoma and six neuroendocrine tumors were observed. According to The Diagnosed and Treated Standard of Breast Carcinoma (2011 version) (8), 46 cases were classified as grade 1 (well differentiated), 66 as grade 2 (moderately differentiated), and 56 as grade 3 (poorly differentiated). In terms of clinical tumor, node, metastasis (TNM) stage, 127 cases were stage I/II and 47 were stage III/IV. There were 43 cases of local and distant lymph node metastasis, and 115 without metastasis. In total, 44 samples were frozen and stored at $-70^{\circ} \mathrm{C}$ for DNA sequencing. In addition, 72 breast intraductal proliferative lesion and 40 normal breast tissue samples were also obtained.

Immunohistochemistry. All specimens were fixed in $10 \%$ neutral formalin, embedded in paraffin and cut into $4-\mu \mathrm{m}$ sections for immunohistochemical staining. The EnVision ${ }^{\mathrm{TM}}$ two-step method was used (DAKO, Hamburg, Germany), as well as the following antibodies: antibodies against $\beta$-catenin, c-myc and cyclin D1, were purchased from Cell Signaling Technology (Danvers, MA, USA) . Prior to staining, sections were pretreated with microwaves for $18 \mathrm{~min}$ in a $0.01 \mathrm{M}$ citrate buffer ( $\mathrm{pH}$ 6.0) for antigen retrieval. 3,3'-Diaminobenzidine was used as a chromogen and $0.01 \mathrm{M}$ phosphate-buffered saline ( $\mathrm{pH}$ 7.4) was substituted for primary antibodies as a negative control.

Evaluation of immunohistochemical staining. Under normal conditions, positive staining of $\beta$-catenin was located within the cytomembrane. According to the method described by Maruyama et al (9), the evaluation of $\beta$-catenin staining is based on its expression in the cytomembrane, cytoplasm, and cell nucleus. Normal expression was observed in $>70 \%$ of the cell expressed in the cytomembrane; reduced expression was observed in the remainder. More than $10 \%$ cells expressed in the cytoplasm or cell nucleus, which was regarded as ectopic expression. Reduced expression and ectopic expression were regarded as abnormal expression.

Positive axin expression was observed in the cell cytoplasm. The evaluation of axin staining was based on the staining intensity and staining cell area, according to the method described by Nakajima et al (10). Staining intensity scores: 0 , no expression; 1 , mildly positive; 2 , moderately positive; and 3, markedly positive. Staining cell area scores: 0 , $<10 \%$ of cells stained; $1,11-25 \%$ stained; $2,26-50 \%$ stained;
$3,>50 \%$ stained. A sum of scores $>2$ was considered to be positive, whereas a score of $<2$ was regarded as negative.

A positive expression of cyclin D1 was observed in the cell nucleus, and c-myc was in the cell nucleus and/or cytoplasm. The slides showed either negative (-), positive (+), or overexpression, depending on the count of positive cells; $<10 \%$ was regarded as negative, $10-50 \%$ was regarded as positive and $>50 \%$ was regarded as overexpression.

Detection of $\beta$-catenin gene exon 3 mutation. DNA was extracted using the phenol-chloroform method for polymerase chain reaction (PCR) amplification with the upstream primer (5'-GCTGATTTGATGGAGTTGGA-3') and the downstream primer (5'-GCTACTTGTTCTTGAGTGAA-3'). PCR conditions included denaturation at $94^{\circ} \mathrm{C}$ for $3 \mathrm{~min}$, amplification for 35 cycles for $40 \mathrm{sec}$ at $94^{\circ} \mathrm{C}$, annealing at $54^{\circ} \mathrm{C}$ for $40 \mathrm{sec}$, and extension at $72^{\circ} \mathrm{C}$ for $60 \mathrm{sec}$. Finally, the samples underwent extension at $72^{\circ} \mathrm{C}$ for $10 \mathrm{~min}$, followed by cooling at $12^{\circ} \mathrm{C}$. The size of the PCR products was $199 \mathrm{bp}$. Synthesis of PCR primers, and purification and direct sequencing of PCR products, was performed by the Beijing Genomics Institute (Beijing, China).

Statistical analysis. Statistical analysis was performed using the Pearson $\chi^{2}$ test. The likelihood ratio and Spearman rank correlation coefficient analysis was performed by SPSS 13.0 software (SPSS, Inc., Chicago, IL, USA). P $<0.05$ was considered to indicate a statistically significant difference.

\section{Results}

Axin, $\beta$-catenin, $c$-myc and cyclin D1 expression in normal breast tissues, breast intraductal proliferative lesions, and breast carcinoma tissues. In the 40 cases with normal breast tissue, the epithelial cells revealed an equally strong membranous expression of $\beta$-catenin protein at the cell-cell boundaries. Axin expression was positive in $87.5 \%$ (35/40) of cases, but the expression of cyclin D1 and c-myc were negative in all cases. In the 72 cases of breast intraductal proliferative lesions, the abnormal rate of $\beta$-catenin expression was $44.44 \%$ (32/72), and the expression of axin was positive in $68.06 \%$ (49/72) of cases. The overexpression of cyclin D1 and c-myc were observed in $33.33 \%$ (24/72) and $27.78 \%$ (20/72) of cases, respectively. In 168 cases of breast carcinoma, positive axin staining was observed in the cytoplasm in $47.62 \%$ (80/168) of cases, amongst which one sample exhibited nuclear axin expression and 11 samples showed membrane and cytoplasmic axin expression (Fig. 1). The abnormal expression rate of $\beta$-catenin was $70.83 \%$ (119/168). The majority of $\beta$-catenin expression was observed in the cytoplasm, whereas membranous staining was reduced or disappeared (Fig. 2). The nuclear expression of $\beta$-catenin was observed in $27.38 \%(46 / 168)$ of cases. The positive expression of cyclin D1 was observed in the cell nucleus (Fig. 3) and c-myc was observed in the cell nucleus and/or cytoplasm (Fig. 4). The overexpression of cyclin D1 and c-myc was observed in 52.98\% (89/168) and 50.00\% (84/168) of cases, respectively.

The abnormal expression rate of $\beta$-catenin was higher in breast carcinoma compared with breast intraductal proliferative lesions $(119 / 168,70.83 \%$ vs. $32 / 72,44.44 \%$; $\mathrm{P}<0.01)$. Positive 

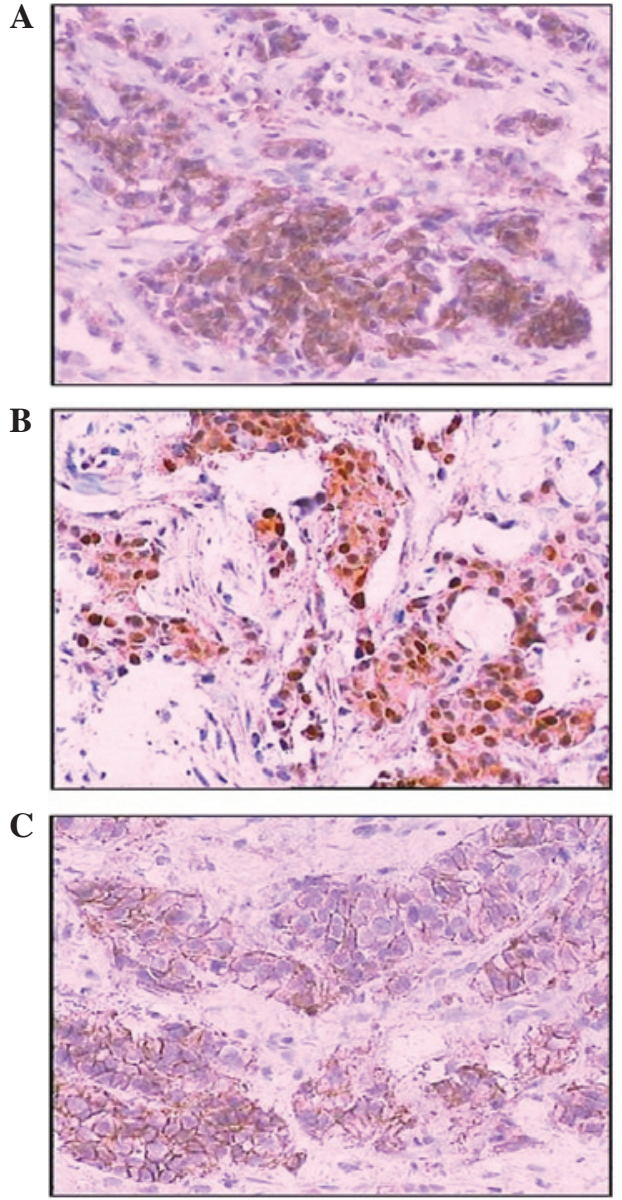

Figure 1. Axin immunohistochemical analysis in breast invasive ductal cancer tissues. (A) Axin expressed predominantly in the cytoplasm. (B) Axin expressed in the nucleus and cytoplasm. (C) Axin expressed in the cytomembrane and cytoplasm. (EnVision staining; Magnification, x200).
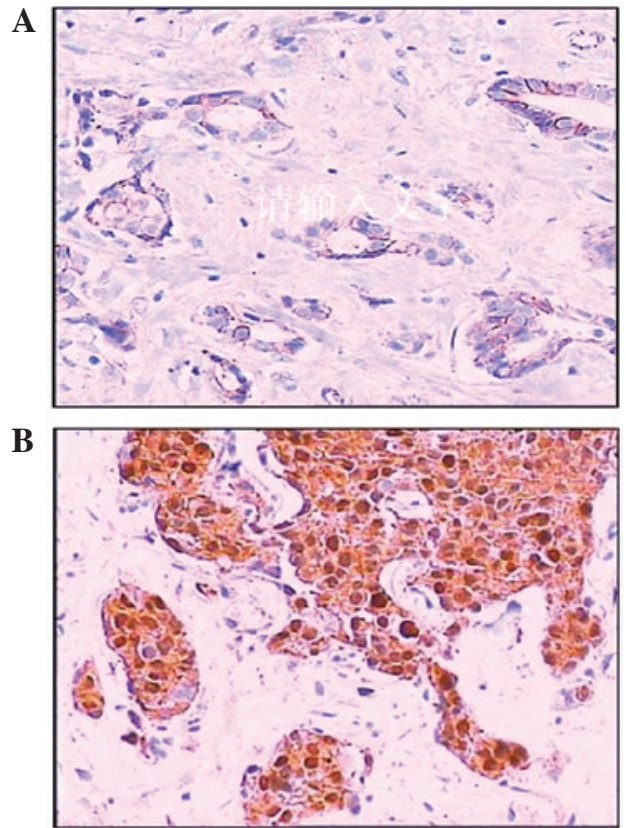

Figure 2. $\beta$-catenin immunohistochemical analysis in breast invasive ductal cancer tissues. (A) Normal expression, $\beta$-catenin expressed in the cytomembrane. (B) Abnormal expression, $\beta$-catenin expressed in the nucleus and cytoplasm. (EnVision staining; Magnification, x200).

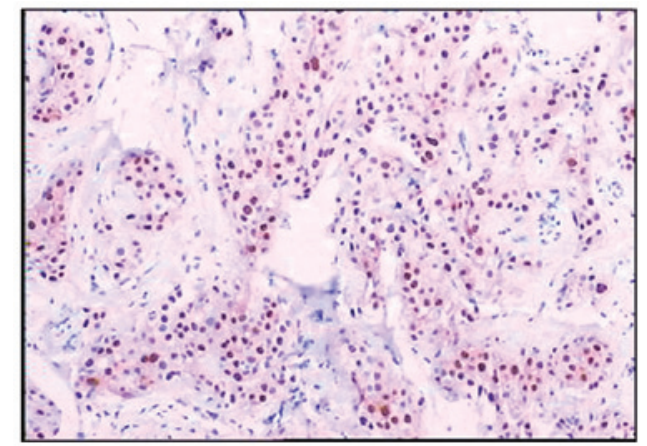

Figure 3. Cyclin D1 immunohistochemical analysis in breast invasive ductal cancer tissues. Cyclin D1 expressed in the cell nucleus (EnVision staining; magnification, $\mathrm{x} 100$ )

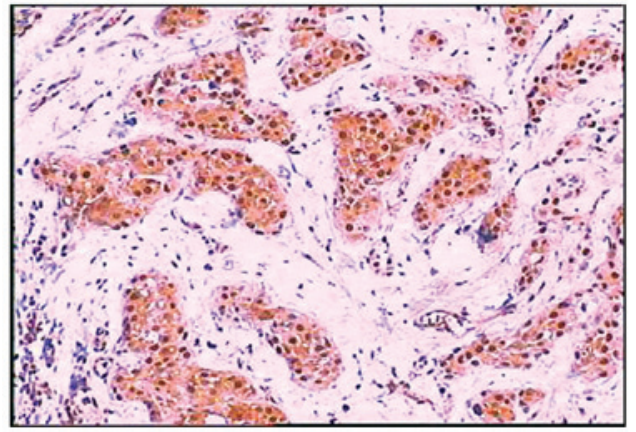

Figure 4. C-myc immunohistochemical analysis in breast invasive ductal cancer tissues. C-myc expressed in the nucleus and cytoplasm (EnVision staining; magnification, x100).

axin expression was lower in breast carcinoma compared with breast intraductal proliferative lesions $(80 / 168,47.62 \%$ vs. $49 / 72,68.06 \% ; \mathrm{P}=0.004)$, and also compared with normal breast tissues $(80 / 168,47.62 \%$ vs. $35 / 40,87.50 \%$; $\mathrm{P}<0.01)$. The overexpression of cyclin D1 and c-myc was higher in breast carcinoma compared with breast intraductal proliferative lesions $(89 / 168,52.98 \%$ vs. 24/72, 33.33\%; $\mathrm{P}<0.01$ and 84/168, $50.00 \%$ vs. $20 / 72,27.78 \%$; $\mathrm{P}<0.01)$, respectively.

Correlation among axin, $\beta$-catenin, $c$-myc and cyclin DI expression, and the clinicopathological characteristics of breast carcinoma. Axin expression was inversely correlated with tumor size, histological grade, clinical TNM stage and lymph node metastasis, but not with patient age or left/right location of the breast carcinoma (Table I). The rate of expression in tumors with a diameter of $>5 \mathrm{~cm}$ was lower than those $2-5 \mathrm{~cm}$ in diameter $(5 / 21,23.81 \%$ vs. $44 / 91,48.35 \% ; \mathrm{P}=0.041)$ and those $<2 \mathrm{~cm}$ in diameter $(5 / 21,23.81 \%$ vs. $31 / 56,55.36 \%$; $\mathrm{P}=0.038$ ), but no difference in axin expression was observed between tumors with a diameter of $<2 \mathrm{~cm}$ and those between $2-5 \mathrm{~cm}$ in diameter $(31 / 56,55.36 \%$ vs. $44 / 91,48.35 \% ; \mathrm{P}=0.409)$. The difference in expression was also observed between tumors with histologic grade I and grade II (37/46, 80.43\% vs. $30 / 66,45.45 \%$; $\mathrm{P}<0.01)$, grade II and grade III $(30 / 66,45.45 \%$ vs. $13 / 56,23.21 \% ; \mathrm{P}<0.01)$, and grade I and grade III $(37 / 46$, $80.43 \%$ vs. $13 / 56,23.21 \%$; $\mathrm{P}<0.01)$. A higher expression rate of axin expression was observed in patients with clinical TNM stage I/II of the disease compared with those with stage III/IV 
Table I. Correlation between axin, $\beta$-catenin, cyclin D1, c-myc and clinicopathological characteristics of breast cancer.

\begin{tabular}{|c|c|c|c|c|c|c|c|c|c|}
\hline \multirow[b]{2}{*}{ Parameter } & \multirow[b]{2}{*}{$\mathrm{n}$} & \multicolumn{2}{|c|}{ Axin } & \multicolumn{2}{|c|}{$\beta$-catenin } & \multicolumn{2}{|c|}{ Cyclin D1 } & \multicolumn{2}{|c|}{ C-myc } \\
\hline & & $\begin{array}{c}\text { Positive } \\
(\%)\end{array}$ & P-value & $\begin{array}{c}\text { Abnormal } \\
(\%)\end{array}$ & P-value & $\begin{array}{c}\text { Positive } \\
(\%)\end{array}$ & P-value & $\begin{array}{c}\text { Positive } \\
(\%)\end{array}$ & P-value \\
\hline \multicolumn{10}{|c|}{ Age (years) } \\
\hline$\leq 50$ & 65 & $28(43.08)$ & 0.349 & $45(69.23)$ & 0.717 & $37(56.92)$ & 0.416 & $37(56.92)$ & 0.154 \\
\hline$>50$ & 103 & $52(50.49)$ & & $74(71.84)$ & & $52(50.49)$ & & $47(45.63)$ & \\
\hline \multicolumn{10}{|l|}{ Site } \\
\hline Left & 82 & $36(43.90)$ & 0.346 & $63(76.83)$ & 0.095 & $46(56.10)$ & 0.429 & $41(50.00)$ & 1.000 \\
\hline Right & 86 & $44(51.16)$ & & $56(65.12)$ & & $43(50.00)$ & & $43(50.00)$ & \\
\hline \multicolumn{10}{|l|}{ Size (cm) } \\
\hline$\leq 2$ & 56 & $31(55.36)$ & 0.046 & $32(57.14)$ & 0.003 & $21(37.50)$ & 0.005 & $18(32.14)$ & 0.005 \\
\hline$>2 \leq 5$ & 91 & $44(48.35)$ & & $67(73.63)$ & & $52(57.14)$ & & $54(59.34)$ & \\
\hline$>5$ & 21 & $5(23.81)$ & & $20(95.24)$ & & $16(76.19)$ & & $12(57.14)$ & \\
\hline \multicolumn{10}{|c|}{ Histological type } \\
\hline IDC & 126 & $51(40.48)$ & 0.001 & $89(70.63)$ & 0.922 & $65(51.59)$ & 0.532 & $63(50.00)$ & 1.000 \\
\hline Others & 42 & $29(69.05)$ & & $30(71.43)$ & & $24(57.14)$ & & $21(50.00)$ & \\
\hline \multicolumn{10}{|c|}{ Histological grade } \\
\hline I & 46 & $37(80.43)$ & $<0.01$ & $30(65.22)$ & 0.003 & $20(43.48)$ & 0.009 & $14(30.43)$ & 0.002 \\
\hline II & 66 & $30(45.45)$ & & $40(60.61)$ & & $30(45.45)$ & & $33(50.00)$ & \\
\hline III & 56 & $13(23.21)$ & & $49(87.50)$ & & $39(69.64)$ & & $37(66.07)$ & \\
\hline \multicolumn{10}{|c|}{ Clinical stage TNM } \\
\hline $\mathrm{I} / \mathrm{II}$ & 127 & $69(54.33)$ & $<0.01$ & $82(64.57)$ & 0.002 & $60(47.24)$ & 0.009 & $60(47.24)$ & 0.209 \\
\hline III/IV & 41 & $11(26.83)$ & & $37(90.24)$ & & $29(70.73)$ & & $24(58.54)$ & \\
\hline \multicolumn{10}{|c|}{$\begin{array}{l}\text { Lymph node } \\
\text { metastasis }\end{array}$} \\
\hline Positive & 53 & $13(24.53)$ & 0.002 & $44(83.02)$ & 0.018 & $39(73.58)$ & $<0.01$ & $34(64.15)$ & 0.013 \\
\hline Negative & 115 & $67(58.26)$ & & $75(65.22)$ & & $50(43.48)$ & & $50(43.48)$ & \\
\hline
\end{tabular}

P values are for multiple comparisons. IDC, invasive ductal carcinoma;TNM, tumor, node, metastasis.

of the disease $(69 / 127,54.33 \%$ vs. $11 / 41,26.83 \%$; $\mathrm{P}<0.01)$. The positive expression rate of axin was $24.53 \%(13 / 53)$ in tumors with lymph node metastasis, in contrast to $58.26 \%(67 / 115)$ in tumors without lymph node metastasis $(\mathrm{P}=0.002)$ (Table I).

The abnormal expression of $\beta$-catenin and the overexpression of cyclin D1 was correlated with tumor size, histological grade, clinical TNM stage and lymph node metastasis, but not with patient age or the location (left/right) of the breast carcinoma (Table I). The abnormal expression of $\beta$-catenin in tumors $>5 \mathrm{~cm}$ in diameter was higher than in those $2-5 \mathrm{~cm}$ in diameter $(20 / 21,95.24 \%$ vs. $67 / 91,73.63 \% ; \mathrm{P}=0.032)$ and in those $<2 \mathrm{~cm}$ in diameter (20/21, $95.24 \%$ vs. $32 / 56,57.14 \%$; $\mathrm{P}=0.001)$. It was also higher in tumors $2-5 \mathrm{~cm}$ in diameter compared with those $<2 \mathrm{~cm}$ in diameter $(67 / 91,73.63 \%$ vs. $32 / 56,57.14 \% ; \mathrm{P}=0.038)$. The overexpression of cyclin D1 in tumors $<2 \mathrm{~cm}$ was less than in those between $2-5 \mathrm{~cm}$ in diameter $(21 / 56,37.50 \%$ vs. 52/91, 57.14\%; $\mathrm{P}=0.021)$ and those tumors $>5 \mathrm{~cm}$ in diameter $(21 / 56,37.50 \%$ vs. $16 / 21$, $76.19 \% ; \mathrm{P}=0.002)$. However, no difference was observed in the overexpression of cyclin D1 between tumors $>5 \mathrm{~cm}$ and those $2-5 \mathrm{~cm}$ in diameter $(16 / 21,76.19 \%$ vs. 52/91, $57.14 \% ; \mathrm{P}=0.107)$. There was a significant difference in the
Table II. Correlation between the expression of $\beta$-catenin, cyclin D1 and c-myc in breast cancer.

\begin{tabular}{|c|c|c|c|c|c|}
\hline \multirow[b]{2}{*}{$\beta$-catenin } & \multirow[b]{2}{*}{$\mathrm{n}$} & \multicolumn{2}{|c|}{ Cyclin D1 } & \multicolumn{2}{|c|}{ C-myc } \\
\hline & & + & - & + & - \\
\hline Abnormal & 119 & 74 & 45 & 65 & 54 \\
\hline Normal & 49 & 15 & 34 & 19 & 30 \\
\hline P-value & & $<0.01$ & & 0.062 & \\
\hline
\end{tabular}

expression of $\beta$-catenin and cyclin D1, respectively, between tumors with a histological grade of grade II and grade III (40/66, $60.61 \%$ vs. $49 / 56,87.50 \%$; $P=0.001 ; 30 / 66,45.45 \%$ vs. $39 / 56,69.64 \% ; \mathrm{P}=0.007)$, and between those with a grade I and grade III $(30 / 46,65.22 \%$ vs. $49 / 56,87.50 \%$; $\mathrm{P}=0.007$; 20/46, $43.48 \%$ vs. $39 / 56,69.64 \%$; $\mathrm{P}=0.008)$. No difference was observed between grade I and grade II tumors (30/46, $65.22 \%$ vs. $40 / 66,60.61 \% ; \mathrm{P}=0.620$ and $20 / 46,43.48 \%$ vs. $30 / 66,45.45 \%$; $\mathrm{P}=0.836)$, respectively. Significant differences 
Table III. Correlation between the expression of axin and $\beta$-catenin in breast cancer.

\begin{tabular}{lcccccc}
\hline & \multicolumn{2}{c}{$\beta$-catenin } & & & \multicolumn{2}{c}{$\beta$-catenin } \\
\cline { 2 - 3 } \cline { 5 - 6 } Axin & Reduced expression in membrane & Normal expression in membrane & & Positive in nuclear & Negative in nuclear \\
\hline+ & 57 & 23 & 8 & 72 \\
P-value & 62 & 26 & & 38 & 50 \\
\end{tabular}

in the abnormal expression of $\beta$-catenin $(82 / 127,64.57 \%$ vs. $37 / 41,90.24 \% ; \mathrm{P}=0.002)$ and the overexpression of cyclin D1 (60/127, 47.24\% vs. 29/41, 70.73\%; $\mathrm{P}=0.009)$ were observed between stage I/II and III/IV of breast carcinoma. Higher rates of abnormal $\beta$-catenin expression $(44 / 53,83.02 \%$ vs. $75 / 115,65.22 \% ; \mathrm{P}=0.018)$ and the rate of overexpression of cyclin D1 (39/53, $73.58 \%$ vs. 50/115, 43.48\%) were observed in the primary tumors of patients with lymph node metastasis compared with those who did not.

The overexpression of c-myc does not correlate with age, left/ right side location of the breast carcinoma, and clinical TNM stage, but does correlate with tumor size, histologic grade, and lymph node metastasis (Table I). The rate of overexpression of c-myc in tumors $<2 \mathrm{~cm}$ in diameter was lower than those with tumors $2-5 \mathrm{~cm}$ in diameter (18/56, 32.14\% vs. 54/91, 59.34\%; $\mathrm{P}=0.001)$ and those $>5 \mathrm{~cm}$ in diameter $(18 / 56,32.14 \%$ vs. $12 / 21$, $57.14 \% ; \mathrm{P}=0.045)$, but no difference in expression was observed between tumors $>5 \mathrm{~cm}$ in diameter and those between $2-5 \mathrm{~cm}$ in diameter $(12 / 21,57.14 \%$ vs. 54/91, 59.34\%; $\mathrm{P}=0.854)$. Significant differences in the expression of c-myc were observed between tumors with a histological grade I and grade II (14/46, 30.43\% vs. $33 / 66,50.00 \% ; \mathrm{P}=0.039)$ and between those with grade I and grade III $(14 / 46,30.43 \%$ vs. $37 / 56,66.07 \%$; $\mathrm{P}<0.01)$, but no difference was observed between histological grade II and grade III tumors $(33 / 66,50.00 \%$ vs. $37 / 56,66.07 \%, \mathrm{P}=0.074)$. The overexpression of c-myc in primary tumors was higher in patients with lymph node metastasis than in those without metastasis $(34 / 53,64.15 \%$ vs. $50 / 115,43.48 \%, \mathrm{P}=0.013)$.

Correlation between the abnormal expression of $\beta$-catenin and the overexpression of cyclin DI and c-myc in breast carcinoma. The abnormal expression of $\beta$-catenin was observed in $74 / 119(62.18 \%)$ cases with cyclin D1-overexpressing tumors and in 65/119 (54.62\%) cases with c-myc overexpressing tumors. There was a positive and significant association between the abnormal expression of $\beta$-catenin and the overexpression of cyclin D1 in breast cancer $(r=0.288, \mathrm{P}<0.01)$, but the abnormal expression was not associated with the overexpression of c-myc in breast cancer $(\mathrm{P}=0.062)$ (Table II).

Correlation between the expression of axin and $\beta$-catenin in breast carcinoma. An increased rate of axin expression was observed in tumors with a nuclear expression of $\beta$-catenin compared with those without $\beta$-catenin nuclear expression $(8 / 46,17.39 \%$ vs. $72 / 122,59.02 \%$; $\mathrm{P}<0.01)$, but the expression of axin was similar in tumors with abnormal (reduced) expression of $\beta$-catenin to those with normal $\beta$-catenin expression (57/119, $47.90 \%$ vs. $23 / 49,46.94 \%$; $\mathrm{P}=0.910)$ (Table III).

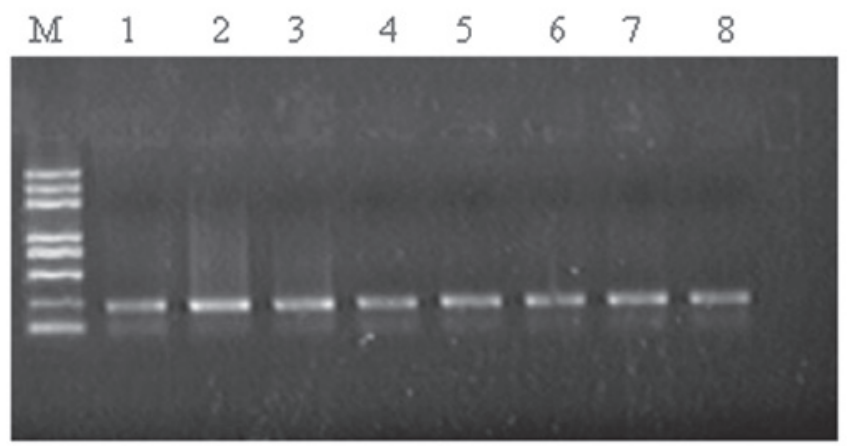

Figure 5. Polymerase chain reaction products of $\beta$-catenin displayed bands at 200 bp. M is a DNA marker (DL2000plus). M, bottom to top: $100 \mathrm{bp}$, $250 \mathrm{bp}, 500 \mathrm{bp}, 750 \mathrm{bp}, 1 \mathrm{~kb}, 2 \mathrm{~kb}, 3 \mathrm{~kb}$ and $5 \mathrm{~kb}$.

Detection of $\beta$-catenin gene exon 3 mutation. The PCR products of $\beta$-catenin displayed bands at $200 \mathrm{bp}$ (Fig. 5). However, mutations in the $\beta$-catenin gene were not detected in 44 cases of breast carcinoma.

\section{Discussion}

$\beta$-catenin was originally identified as a cytoplasmic protein that links E-cadherin and $\alpha$-catenin to the cytoskeleton constituting the E-cadherin-catenin complex in order to maintain normal epithelial polarity and intercellular adhesion, and to regulate cellular differentiation and proliferation (6). $\beta$-catenin has been reported to be a critical member of the canonical Wnt/ $\beta$-catenin pathway, which promotes cell fate determination, proliferation and survival. In the absence of Wnt signals, $\beta$-catenin in the cytoplasm is sequestered into a complex with the adenomatous polyposis coli tumor suppressor, axin and a serine threonine glycogen synthetase kinase-3 $\beta$ (GSK-3 $\beta$ ), enabling the phosphorylation and degradation of free $\beta$-catenin by a ubiquitin-proteasome system. The activation of canonical Wnt signaling inhibits the degradation of $\beta$-catenin, allowing it to accumulate within the cytoplasm and enter the nucleus, where it interacts with Lef/Tcfs to regulate gene expression. Wnt/ $\beta$-catenin signaling has been documented in a wide range of cancers, including colorectal and gastric cancer, melanoma, and tumors derived from hepatic, breast and prostate tissue. Numerous studies have suggested that the activation of the Wnt/ $\beta$-catenin signaling pathway is important in human tumorigenesis (3-5). However, reports regarding the expression of $\beta$-catenin in human breast cancer have been controversial. Bankfalvi et al (11) reported that the abnormal expression of $\beta$-catenin is an early event in breast cancer, as 
reduced $\beta$-catenin membrane expression was noted during the development of invasive carcinoma from normal breast tissue. Other studies have reported that the abnormal expression of $\beta$-catenin was associated with a poor prognosis in breast cancer (12-15), and $\beta$-catenin was deemed to be an independent prognostic factor. Chung et al (16) demonstrated that patients with tumors coexpressing high levels of abnormal $\beta$-catenin and p53 had poor survival outcomes, therefore $\beta$-catenin may not be an independent prognostic factor. Wang et al (17) observed a correlation between $\beta$-catenin and Her 2 expression, and this correlation may synergistically promote lymph node metastasis in breast cancer. In the present study study, $>70 \%$ of abnormal $\beta$-catenin expression was observed in breast carcinomas, which was higher than in breast intraductal proliferative lesions. The nuclear expression rate of $\beta$-catenin was $27.38 \%$ (46/168). Abnormal expression was significantly associated with histological grade, clinical TNM stage and lymph node metastasis. The abnormal expression of $\beta$-catenin may be important in breast carcinogenesis as an independent prognostic factor.

Mutations of $\beta$-catenin, which result in the accumulation of $\beta$-catenin in the cytoplasm and nucleus, are identified in a wide variety of human cancers, including colon cancer, desmoid, gastric cancer, hepatocarcinoma, medulloblastoma, melanoma, ovarian, pancreatic and prostate cancers $(18,19)$. The $\beta$-catenin gene is located on chromosome $3 \mathrm{p} 21$, it is $23.2 \mathrm{~kb}$ and has 16 exons. Exon 3 is clustered in the domain that contains an ubiquitination motif (codons 32 through to 37 ) and four conserved GSK-3 $\beta$ phosphorylation sites (Ser33, Ser37, Thr41 and Ser45). Normally, $\beta$-catenin gene mutations occur in exon 3 (18). Zhuang et al (20) identified mutations of the $\beta$-catenin gene in 1,3-butadiene-induced B6C3F1 mice mammary adenocarcinomas and identified missense mutations in codons 33,34 , and 41 of $\beta$-catenin in $18 \%(3 / 17)$ of tumors. By contrast, such mutations rarely exist in human breast cancer (21-23). $\beta$-catenin mutations were detected in $45 \%$ of breast fibromatosis cases in the study (24). PCR and direct sequencing on DNA from 44 breast carcinoma tissue samples was conducted, but no mutations were identified. It is possible that the mutation in exon 3 of the $\beta$-catenin gene in human breast cancer may be a rare event and not a predominant mechanism for abnormal $\beta$-catenin expression. Other mechanisms may result in the abnormal expression of $\beta$-catenin, which requires further study.

Axin was originally identified as the product of the mouse gene termed Fused (25). Axin, a scaffold protein, is a multidomain protein that interacts with multiple proteins and functions as a negative regulator of Wnt signaling by downregulating $\beta$-catenin levels. It is also important in the JNK signaling pathway. Axin controls diverse cellular functions in proliferation, fate determination and the suppression of tumorigenesis (7). Several studies have identified axin expression in various human cancers, and have demonstrated an inverse association between axin expression and tumor invasion and metastasis (26-28). However, there have been few studies regarding axin expression in human breast cancer, and knowledge regarding axin and $\beta$-catenin expression in human breast cancer is limited. In this study, the positive expression of axin was $47.62 \%$ in breast carcinoma, which was lower than the positive expression in breast intraductal proliferative lesions and in normal breast tissues. Axin expression was inversely correlated with tumor size, histological grade, clinical TNM stage and lymph node metastasis. The expression was negatively correlated with $\beta$-catenin nuclear expression, but was not correlated with the reduced membranous expression of $\beta$-catenin. It has been postulated that axin expression may downregulate the accumulation of $\beta$-catenin in the nucleus and inhibit the loss of differentiation and proliferation of tumor cells in breast carcinoma. In addition, Axin is considered to be a cytoplasmic protein. Cong et al (29) reported that axin functions as a molecular chaperone for $\beta$-catenin and that the nuclear-cytoplasmic shuttling of axin regulates the nuclear-cytoplasmic distribution of $\beta$-catenin. In the present study, nuclear axin expression was only identified in one sample, indicating that axin may act as a shuttle in and out of the nucleus. However, the reason for infrequent nuclear axin expression in tumor tissues remains unknown. Cliffe et al (30) reported that the dishevelled protein, an upstream component of the Wnt/ $\beta$-catenin pathway, may relocate axin from the cytoplasm to the plasma membrane and allow the subsequent inactivation of the axin complex by Wingless signaling. In the present study, 11 samples were observed to have membranous and cytoplasmic axin expression, thus further investigation is required.

Cyclin D1 and c-myc are oncogenes involved in cell proliferation, differentiation and apoptosis. As target genes of the Wnt signaling pathway, the amplification and/or overexpression of cyclin D1 and c-myc in tumor cells are extremely common, indicating that they are essential components during carcinogenesis. In breast carcinoma, Ozaki et al (31) observed a strong correlation between the overexpression of $\beta$-catenin, and cyclin D1 and c-myc. Roh et al (32) reported that the abnormal expression of $\beta$-catenin may upregulate the overexpression of c-myc. Lin et al (12) observed that the abnormal expression of $\beta$-catenin was associated with the overexpression of cyclin D1, whereas Lim et al (13) did not. In the present study, the levels of overexpression of cyclin D1 and c-myc in breast carcinoma were 53 and 50\%, respectively, which were higher than those in the breast intraductal proliferative lesions. The overexpression of cyclin D1 was significantly correlated with tumor size, histological grade, clinical TNM stage and lymph node metastasis, whereas the overexpression of c-myc was correlated with tumor size, histological grade and lymph node metastasis. There was a positive correlation between the abnormal expression of $\beta$-catenin and the overexpression of cyclin D1 in breast cancer, but that association was not observed between the abnormal expression of $\beta$-catenin and the overexpression of c-myc. The abnormal expression of $\beta$-catenin may be key in the carcinogenesis and progression of human breast carcinoma by upregulating the expression of cyclin D1. Cyclin D1 and c-myc overexpression may be considered to be useful markers for determining metastasis and providing a prognosis of human breast carcinoma and to aid in guiding treatment.

\section{References}

1. Paul S and Dey A: Wnt signaling and cancer development: therapeutic implication. Neoplasma 55: 165-176, 2008. 
2. Prosperi JR and Goss KH: A Wnt-ow of opportunity: targeting the Wnt/beta-catenin pathway in breast cancer. Curr Drug Targets 11: 1074-1088, 2010

3. Miller JR: The Wnts. Genome Biol 3: 1-15, 2002.

4. Polakis P: Wnt signaling and cancer. Genes Dev 14: 1837-1851, 2000.

5. Lustig B and Behrens J: The Wnt signaling pathway and its role in tumor development. J Cancer Res Clin Oncol 129: 199-221, 2003.

6. Van Aken E, De Wever O, Correia da Rocha AS and Mareel M: Defective E-cadherin/catenin complexes in human cancer. Virchows Arch 439: 725-751, 2001.

7. Luo W and Lin SC: Axin: a master scaffold for multiple signaling pathways. Neurosignals 13: 99-113, 2004.

8. Böcker W: WHO classification of breast tumors and tumors of the female genital organs: pathology and genetics. Verh Dtsch Ges Pathol 86: 116-119, 2002 (In German).

9. Maruyama K, Ochiai A, Akimoto S, et al: Cytoplasmic beta-catenin as a predictor of hematogenous metastasis in human colorectal cancer. Oncology 59: 302-309, 2000.

10. Nakajima M, Fukuchi M, Miyazaki T, et al: Reduced expression of Axin correlates with tumour progression of oesophageal squamous cell carcinoma. Br J Cancer 88: 1734-1739, 2003.

11. Bankfalvi A, Terpe HJ, Breukelmann D, et al: Immunophenotypic and prognostic analysis of E-cadherin and beta-catenin expression during breast carcinogenesis and tumour progression: a comparative study with CD44. Histopathology 34: 25-34, 1999.

12. Lin SY, Xia W, Wang JC, et al: Beta-catenin , a novel prognostic marker for breast cancer: its roles in cyclin D1 expression and cancer progression. Proc Natl Acad Sci USA 97: 4262-4266, 2000

13. Lim SC and Lee MS: Significance of E-cadherin/beta-catenin complex and cyclin D1 in breast cancer. Oncol Rep 9: 915-928,2002.

14. Dolled-Filhart M, McCabe A, Giltnane J, et al: Quantitative in situ analysis of beta-catenin expression in breast cancer shows decreased expression is associated with poor outcome. Cancer Res 66: 5487-5494, 2006.

15. López-Knowles E, Zardawi SJ, McNeil CM, et al: Cytoplasmic localization of beta-catenin is a marker of poor outcome in breast cancer patients. Cancer Epidemiol Biomarkers Prev 19: 301-309, 2010.

16. Chung GG, Zerkowski MP, Ocal IT, et al: beta-Catenin and $\mathrm{p} 53$ analyses of a breast carcinoma tissue microarray. Cancer 100 : 2084-2092, 2004.

17. Wang Z, Ren Y, He JJ, et al: Relationship between ectopic expression of Wnt/beta-catenin signaling pathway and Her-2 overexpression in human breast carcinoma. J Xi'an Jiaotong Univ (Med Sci) 30: 587-591, 2009.
18. Kikuchi A: Tumor formation by genetic mutations in the components of the Wnt signaling pathway. Cancer Sci 94: 225-229, 2003

19. He YJ, Jia XS, Qing SKZ, et al: The study on p53 and beta-catenin gene mutations in NK/T cell lymphoma. Chin J Clin Oncol 31: 1385-1388, 2004

20. Zhuang SM, Wiseman RW and Söderkvist P: Frequent mutations of the Trp53, Hras1 and beta-catenin (Catnb) genes in 1,3-butadiene-induced mammary adenocarcinomas in $\mathrm{B} 6 \mathrm{C} 3 \mathrm{~F} 1$ mice. Oncogene 21: 5643-5648, 2002.

21. Howe LR and Brown AM: Wnt signaling and breast cancer. Cancer Biol Ther 3: 36-41, 2004.

22. Ozaki S, Ikeda S, Ishizaki Y, et al: Alterations and correlations of the components in the Wnt signaling pathway and its target genes in breast cancer. Oncol Rep 14: 1437-1443, 2005.

23. Kizildag S, Zengel B, Vardar E, et al: beta-catenin gene mutation in invasive ductal breast cancer. J BUON 13: 533-536, 2008.

24. Abraham SC, Rcynolds C, Lee JH, et al: Fibromatosis of the breast and mutations involving the APC/beta-catenin pathway. Hum Pathol 33: 39-46, 2002.

25. Zeng L, Fagotto F, Zhang T, et al: The mouse Fused locus encodes Axin, an inhibitor of the Wnt signaling pathway that regulates embryonic axis formation. Cell 90: 181-192, 1997.

26. Xu HT, Wang L, Lin D, et al: Abnormal beta-catenin and reduced axin expression are associated with poor differentiation and progression in non-small cell lung cancer. Am J Clin Pathol 125: 534-541, 2006.

27. Ishizaki Y, Ikeda S, Fujimori M, et al: Immunohistochemical analysis and mutational analyses of beta-catenin, Axin family and APC genes in hepatocellular carcinomas. Int J Oncol 24: 1077-1083, 2004

28. Jin LH, Shao QJ, Luo W, et al: Detection of point mutations of the Axin1 gene in colorectal cancers. Int J Cancer 107: 696-699, 2003.

29. Cong F, Varmus H: Nuclear-cytoplasmic shuttling of Axin regulates subcellular localization of beta-catenin. Proc Natl Acad Sci USA 101: 2882-2887, 2004.

30. Cliffe A, Hamada F, Bienz M: A role of Dishevelled in relocating Axin to the plasma membrane during wingless signaling. Curr Biol 13: 960-966, 2003

31. Roh MS, Hong SH, Jeong JS, et al: Gene expression profiling of breast cancer with emphasis of beta-catenin regulation. J Korean Med Sci 19: 275-282, 2004. 